\section{Commentary: If a patient's life is at stake, let's not stop at the surface of the curves}

\author{
Francesco Pollari, MD, $\mathrm{PhD}$, and \\ Michele Di Mauro, MD, PhD, $\mathrm{MSc}^{\mathrm{b}}$
}

The Journal does not only publish original research articles, which are obviously of an excellent level, but it also provides articles concerning the statistical method and the practical implications.

The article by Movahedi and colleagues ${ }^{1}$ is just 1 of them. The authors detail how a receiver operating characteristic (ROC) curve works and what erroneous messages it can deliver under certain conditions - which (unfortunately or may be not) occur very often in medicine. In fact, the problem focused on by this article is a very common phenomenon called the imbalance of the data. What every score does (and for the same reason is defined as a classifier) is to assign labels (eg, dead or alive) to patients. Consequently, every score assigns patients to 4 categories: the true dead, the false (labeled) dead, the true surviving, and the false (labeled) surviving. If the numbers of patients in these categories is unequal, there we have the unbalancing of data and the ROC curve could lead to an overly optimistic interpretation of the score's performance. The authors offer as an example 2 mortality scores used to predict the outcome after left ventricular assist device implantation (namely the HeartMarte Risk Score ${ }^{2}$ and the Random Forest ${ }^{3}$ ), but indeed their observations can be applied to any other scores. Movahedi and colleagues ${ }^{1}$ discuss the problem and suggest - as a solution - the use of a supplemental evaluation tool: The precision-recall curve. ${ }^{4}$

\footnotetext{
From the ${ }^{\text {a Department }}$ of Cardiac Surgery, Klinikum Nürnberg, Paracelsus Medical University, Nuremberg, Germany; and ${ }^{\mathrm{b} C}$ ardiothoracic Surgery Department, Heart and Vascular Center, Maastricht University Medical Center, Maastricht, The Netherlands.

Disclosures: The authors reported no conflicts of interest.

The Journal policy requires editors and reviewers to disclose conflicts of interest and to decline handling or reviewing manuscripts for which they may have a conflict of interest. The editors and reviewers of this article have no conflicts of interest.

Received for publication Aug 7, 2021; revisions received Aug 7, 2021; accepted for publication Aug 9, 2021; available ahead of print Aug 14, 2021.

Address for reprints: Michele Di Mauro, MD, PhD, MSc, Cardiothoracic Surgery Department, Heart and Vascular Center, Maastricht University Medical Center, P De-byelaan 25,6202 AZ, Maastricht, The Netherlands (E-mail: mdimauro1973@ gmail.com).

J Thorac Cardiovasc Surg 2023; 165:1447-8

$0022-5223 / \$ 36.00$

Copyright (C) 2021 by The American Association for Thoracic Surgery

https://doi.org/10.1016/j.jtcvs.2021.08.025
}

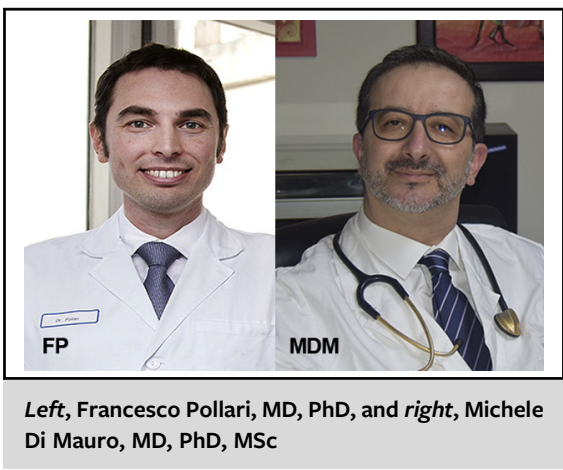

CENTRAL MESSAGE

Imbalanced data could lead to an overoptimistic performance of ROC curve analysis. The use of precision-recall curves and calibration tests are recommended.

The ROC curve is among the most-used tools in medical statistics, and for this reason, it risks being abused. Like other things in life, ROC analysis was invented for other purposes (it was developed during World War II to decide whether a radar signal was an enemy airplane or not, and eventually whether or not to shoot it down ${ }^{5}$ ) and is now commonly applied by the medical-scientific community to identify what probability a patient has to survive an intervention. Given the ethical implications (of the intervention sure, but also of shooting down an airplane) it is necessary to understand with great care the limits of this technique and to consider more parameters before taking action (eg, the precision-recall curve, but without forgetting calibration tests such as the Brier score). ${ }^{6}$

The Roman poet Carlo Alberto Camillo Mariano Salustri (1871-1950), also known as Trilussa, effectively summarized in his satirical verses the limits of statistics, especially in the case of imbalanced data: "According to statistic, everyone has a chicken. And if you do not have any, that means some other owns 2." Obviously if you are the person without a chicken and you are hungry, it is not of statistical significance.

\section{References}

1. Movahedi F, Padman R, Antaki JF. Limitations of receiver operating characteristic curve on imbalanced data: assist device mortality risk scores. J Thorac Cardiovasc Surg. 2023;165:1433-42.e2.

2. Adamo L, Nassif M, Tibrewala A, Novak E, Vader J, Silvestry SC, et al. The Heartmate Risk Score predicts morbidity and mortality in unselected left ventricular assist device recipients and risk stratifies INTERMACS class 1 patients. JACC Heart Fail. 2015;4:283-90.

3. Smedira NG, Blackstone EH, Ehrlinger J, Thuita L, Pierce CD, Moazami N, et al Current risks of HeartMate II pump thrombosis: non-parametric analysis of 
Interagency Registry for Mechanically Assisted Circulatory Support data. J Heart Lung Transplant. 2015;34:1527-34.

4. Saito T, Rehmsmeier M. The precision-recall plot is more informative than the ROC plot when evaluating binary classifiers on imbalanced datasets. PLoS One. 2015;10:e0118432.
5. Ferraris VA. Commentary: should we rely on receiver operating characteristic curves? From submarines to medical tests, the answer is a definite maybe! $J$ Thorac Cardiovasc Surg. 2019;157:2354-5.

6. Murphy AH. A new vector of partition of the probability score. J Appl Meteorol. 1973;12:595-600. 